\title{
Response of Potato Cultivars to Five Isolates Belonging to Four Strains of Potato virus $Y$
}

Bihua Nie, National Center for Vegetable Improvement (Central China), MOE Key Laboratory of Horticultural Plant Biology, Hubei Provincial Research Center of Potato Engineering and Technology, Huazhong Agricultural University, Wuhan, 430070, China, and Potato Research Centre, Agriculture and Agri-Food Canada, P.O. Box 20280, 850 Lincoln Road, Fredericton, New Brunswick, E3B 4Z7, Canada; Mathuresh Singh, Agricultural Certification Services, 1030 Lincoln Road, Fredericton, New Brunswick, E3B 8B7, Canada; Agnes Murphy, Potato Research Centre, Agriculture and Agri-Food Canada; Andrew Sullivan, Plant Propagation Centre, New Brunswick Department of Agriculture, Aquaculture and Fisheries, 850 Lincoln Road, Fredericton, New Brunswick, E3B 5H1, Canada; Conghua Xie, National Center for Vegetable Improvement (Central China), MOE Key Laboratory of Horticultural Plant Biology; and Xianzhou Nie, Potato Research Centre, Agriculture and Agri-Food Canada

\begin{abstract}
Nie, B., Singh, M., Murphy, A., Sullivan, A., Xie, C., and Nie, X. 2012. Response of potato cultivars to five isolates belonging to four strains of Potato virus $Y$. Plant Dis. 96:1422-1429.

The responses of 14 potato cultivars to five Potato virus $Y$ (PVY) isolates belonging to four strains (ordinary $\left[\mathrm{PVY}^{\mathrm{O}}\right]$, tobacco veinal necrosis $\left[\mathrm{PVY}^{\mathrm{N}}\right], \mathrm{N}: \mathrm{O}$ group $\left[\mathrm{PVY}^{\mathrm{N}: \mathrm{O}}\right]$, and nonrecombinant potato tuber necrotic $\left[\mathrm{PVY}^{\mathrm{NTN}}\right]$ ) were studied in primary and secondary infections. For the primary infection experiments, foliage symptoms were monitored daily after mechanical inoculation with a PVY isolate until harvest; and, for the secondary infection experiments, foliage symptoms were monitored regularly from plant emergence until harvest. Tuber symptoms (namely, tuber necrotic ringspots) were checked at harvest and monthly postharvest for up to 4 months. In both infections, symptoms varied significantly depending on potato cultivar and virus strain or isolate. In primary infections, local lesions occurred on inoculated leaves of 'AC Chaleur', 'Eramosa', 'Goldrush', 'Jemseg', 'Katahdin', 'Ranger Russet', and 'Yukon Gold' after inoculation with PVYO isolates, followed by systemic necrosis on latterly emerged uninoculated leaves. In contrast, plants of 'CalWhite', 'La Rouge',

'Red LaSoda', 'Russet Burbank', 'Russet Norkotah', and 'Superior' did not exhibit any visible symptoms on inoculated leaves but developed mild to severe mosaic on latterly emerged leaves after infection with $\mathrm{PVYO}$ isolates. In all cultivars, near-symptomless to mild mosaic was induced by $\mathrm{PVY}^{\mathrm{N}}$ and mild to severe mosaic by PVY ${ }^{\mathrm{N}: O}$. PVY ${ }^{\mathrm{NTN}}$ induced mild to severe mosaic in plants of all cultivars except AC Chaleur, 'Cherokee', and Yukon Gold, which developed visible systemic necrosis. Necrotic ringspots were observed in tubers of PVY ${ }^{\mathrm{NTN}}$-infected plants of AC Chaleur, Cherokee, and Yukon Gold. The tuber symptoms were also incited by PVY ${ }^{\mathrm{N}}-\mathrm{Jg}$ on Cherokee. In secondary infections, the symptoms were generally more severe than primary infections even though the symptom types did not alter. As in the greenhouse, a clear symptom severity pattern (PVYO FL $>\mathrm{PVY}^{\mathrm{O}}-\mathrm{RB}>\mathrm{PVY}^{\mathrm{NTN}}-\mathrm{Sl}>\mathrm{PVY}^{\mathrm{N}: \mathrm{O}}-\mathrm{Mb} 58>\mathrm{PVY}^{\mathrm{N}}-\mathrm{Jg}$ ) was observed in AC Chaleur, Cherokee, Eramosa, Goldrush, Jemseg, Katahdin, Ranger Russet, and Yukon Gold in the field.
\end{abstract}

Potato virus $Y$ (PVY) is the type member of the genus Potyvirus in the family Potyviridae. It infects several important crops in the Solanaceae family, including potato, tobacco, tomato, and pepper $(4,26)$. PVY is ubiquitous in distribution, causing significant yield loss and quality degradations on the potato crop worldwide $(7,19,21,26,31)$. A great diversity in strains of PVY has been noted and several main strain groups have been classified $(9,11,12$, 21,32). In general, these strain groups can be categorized into nonrecombinant and recombinant categories. The former includes the common (ordinary) strain $\left(\mathrm{PVY}^{\mathrm{O}}\right)$, the potato stipple streak strain $\left(\mathrm{PVY}^{\mathrm{C}}\right)$, the tobacco veinal necrosis strain $\left(\mathrm{PVY}^{\mathrm{N}}\right)$, and its derivative, the nonrecombinant potato tuber necrotic strain (North American [NA]-PVY $\left.{ }^{\mathrm{NTN}}\right)(15-17)$. The latter includes the $\mathrm{N}: \mathrm{O}$ group (PVY ${ }^{\mathrm{N}: \mathrm{O}}$ or $\mathrm{PVY}^{\mathrm{N}}$-Wilga) $(6,18)$ and the recombinant $\mathrm{PVY}^{\mathrm{NTN}}$, which can be further divided into European (Eu)-PVY ${ }^{\mathrm{NTN}}$ (15-17) and PVY ${ }^{\mathrm{NTN}-\mathrm{NW}}$ (2) or PVY ${ }^{\mathrm{NTN}}-\mathrm{HN} 2(9,10)$. The two recombinant $\mathrm{PVY}^{\mathrm{NTN}}$ groups differ from each other at the third recombination junction (recombinant joint $[\mathrm{RJ}] 3$ ). In Eu-PVY ${ }^{\mathrm{NTN}}$,

Corresponding author: X. Nie, E-mail: xianzhou.nie@agr.gc.ca

* The $\boldsymbol{e}$-Xtra logo stands for "electronic extra" and indicates that 4 supplementary figures and 2 supplementary tables are available online.

Accepted for publication 1 May 2012.

http://dx.doi.org/10.1094/PDIS-01-12-0018-RE

(c) 2012 Department of Agriculture and Agri-Food, Government of Canada the $\mathrm{RJ} 3$ occurs at the $3^{\prime}$ proximal end of the coat protein $(\mathrm{CP})$ gene at approximately nucleotide 9,100 , thus leading to a PVYN-type of $\mathrm{CP}$ and a PVY ${ }^{\mathrm{N}}$ serotype; whereas, in $\mathrm{PVY}^{\mathrm{NTN}-\mathrm{NW}} / \mathrm{PVY}^{\mathrm{NTN}}-\mathrm{HN} 2$, the RJ3 is located prior to the $\mathrm{CP}$ gene at nucleotide 8,700 , thus leading to a PVY ${ }^{\mathrm{O}}$-type of $\mathrm{CP}$ and a PVY ${ }^{\mathrm{O}}$ serotype $(2,9,10)$. It is noteworthy that Eu-PVYNTN has been reported in many potatogrowing areas in the world, whereas the $\mathrm{PVY}^{\mathrm{NTN}-\mathrm{NW}} / \mathrm{PVY}^{\mathrm{NTN}}-\mathrm{HN} 2$ has only been reported in Syria and China to date $(2,9,10)$.

An increase in PVY incidence in potato crops has been observed in North America over the last decade $(3,7,19,21,29)$. This increase is at least partially due to the emergence of novel PVY strains or isolates that may cause only mild symptoms in most commonly grown cultivars and by the increased production of susceptible cultivars that do not develop clear-cut symptoms, thus evading symptom-based rogueing and field inspections (7). Considering the significance of symptom recognition in PVY management, characterization of different potato cultivars in response to infection by different PVY strain or isolate groups is of great interest to potato growers and the field inspectors.

Symptom expression in host plants upon PVY infection is determined by the virus strain, isolate, or variant type and the host plant species and its genotype $(24,25)$. It is further affected by environmental factors (e.g., temperature and light intensity), plant physiological conditions (e.g., plant age), and, more importantly, whether the infection is primary (current season infection) or secondary (tuber-borne) $(5,24,33)$. The symptoms induced by $\mathrm{PVY} \mathrm{Y}^{\mathrm{O}}$ includes mild to severe mosaic, leaf and stem necrosis and leaf drop in many potato cultivars, and mosaic on tobacco $(7,22,29)$. Symptoms elicited by $\mathrm{PVY}^{\mathrm{N}}$ are generally milder than $\mathrm{PVY}^{\mathrm{O}}$ in most potato 
cultivars, ranging from symptomless to mild to severe mosaic, with severe veinal, petiole and stem necrosis, and premature leaf death occurring on infected tobacco $(4,17,21,22,28)$. PVY ${ }^{\mathrm{N}: \mathrm{O}}$ and $\mathrm{PVY}^{\mathrm{NTN}}$ induce $\mathrm{PVY}^{\mathrm{N}}$-like symptoms on tobacco plants and generally cause more severe symptoms, including distinct mosaic or chlorotic mottling on potato foliage, than $\mathrm{PVY}^{\mathrm{N}}$. Moreover, $\mathrm{PVY}^{\mathrm{NTN}}$ can cause necrotic ringspots on tubers of susceptible potato cultivars $(1,7)$. Despite the general knowledge of symptomatology of PVY strains on potato, no systematic studies have been carried out to elucidate symptom expression in potato cultivars after being infected with different PVY isolates or strains. This article reports a study of responses of 14 potato cultivars to five distinct $\mathrm{PVY}$ isolates belonging to four strains $\left(\mathrm{PVY} \mathrm{Y}^{\mathrm{O}}\right.$, $\mathrm{PVY}^{\mathrm{N}: \mathrm{O}}, \mathrm{Eu}-\mathrm{PVY} \mathrm{NTN}^{\mathrm{N}}$, and NA-PVY ${ }^{\mathrm{N}}$ ) in both primary and secondary infections under greenhouse and field conditions. Differential symptom expression and disease development for each cultivar in response to infection with different PVY isolates were investigated and presented.

\section{Materials and Methods}

Virus isolates and potato cultivars. Five PVY isolates$\mathrm{PVY}^{\mathrm{O}}$-FL (a severe $\mathrm{PVY} \mathrm{Y}^{\mathrm{O}}$ isolate), $\mathrm{PVY}^{\mathrm{O}}$-RB (a mild PVY $\mathrm{P}^{\mathrm{O}}$ isolate), $\mathrm{PVY}^{\mathrm{N}: \mathrm{O}}-\mathrm{Mb} 58, \mathrm{PVY}^{\mathrm{N}}-\mathrm{Jg}$, and $\mathrm{PVY}^{\mathrm{NTN}}-\mathrm{Sl}$ (14-18)-were used in this study. Viruses were maintained in tobacco hosts in the greenhouse at the Potato Research Centre, Agriculture and AgriFood Canada (PRC-AAFC). Prior to the inoculation, the strain or isolate identity and purity was verified by reverse-transcription polymerase chain reaction (RT-PCR) and enzyme-linked immunosorbent assay (ELISA) as described previously (14-18,29).

Virus-free tissue culture plantlets of 14 potato cultivars (namely, 'AC Chaleur', 'CalWhite', 'Cherokee', 'Eramosa', 'Goldrush', 'Jemseg', 'Katahdin', 'La Rouge', 'Ranger Russet', 'Red LaSoda', 'Russet Burbank', 'Russet Norkotah', 'Superior', and 'Yukon Gold') were obtained from the Plant Propagation Centre (New Brunswick Department of Agriculture, Aquaculture and Fisheries). The plantlets were transplanted to 6 -in. $(15.2 \mathrm{~cm})$ pots containing premixed soil in the greenhouse with a cycle of 16 and $8 \mathrm{~h}$ (light and darkness, respectively). The ambient light was supplemented with artificial light or shading to give a light intensity of $90 \mu \mathrm{m}^{2} / \mathrm{s}$. The temperature was 18 to $22^{\circ} \mathrm{C}$ and the humidity was $75 \%$.

Virus inoculation and symptom observation. For the primary infection experiments, four potato tissue culture plantlets of each cultivar were mechanically inoculated with PVY isolates on each of the three uppermost leaves at the six-leaf stage as described previously (29), and grown in a greenhouse. Plantlets inoculated with the inoculation buffer (mock) $(10 \mathrm{mM}$ phosphate buffer, $\mathrm{pH}$
7.5, with $32 \mathrm{mM}$ sodium sulfite) served as control treatments. Foliage symptoms were monitored daily after inoculation until harvest. For each pot, tubers were harvested and observed. Tuber symptoms, mainly necrotic ringspots or potato tuber necrotic ringspot disease (PTNRD), were checked at harvest and monthly post harvest for up to 4 months. The experiments were repeated two times. In the first repeat, the differences of tuber yield between virusinoculated plants and mock-inoculated (control) plants were visually observed and estimated. In the second repeat, the yield of each plant was measured and statistically analyzed using a $t$ test.

Tubers resulting from the above plants were used for the secondary infection experiments in both the greenhouse and field. The experiments were repeated two times, each using tubers resulting from one of the two primary infection experiments. For the secondary infection experiments in the greenhouse, one progeny tuber from each of the above primarily infected plants were planted in 6in. $(15.2 \mathrm{~cm})$ pots and grown in a greenhouse under the conditions described above. Foliage symptoms, including the symptom type and symptom development, were recorded every other day after plant emergence until harvest. Upon harvest, tubers from each plant were observed for PTNRD. The tubers were reexamined for PTNRD monthly post harvest for up to 4 months. The impact of PVY infection on yield was measured as described above in the primary infection experiments.

For the secondary infection experiments in the field, 10 progeny tubers of the primarily infected plants from each virus isolatepotato cultivar combination were planted in one row, 3 feet $(91.4$ $\mathrm{cm}$ ) apart in the field plots at PRC-AAFC in the 2010 and 2011 growing seasons (late May to early October). All treatments of the same cultivar were planted side by side with the sequence of PVY ${ }^{\mathrm{O}}-\mathrm{FL}, \mathrm{PVY} \mathrm{O}^{\mathrm{O}} \mathrm{RB}, \mathrm{PVY} \mathrm{N}^{\mathrm{N}: \mathrm{O}}, \mathrm{PVY}^{\mathrm{NTN}}, \mathrm{PVY}^{\mathrm{N}}$, and mock. The plants were tested for infection with the intended PVY isolates by RT-PCR and ELISA, as described below. The plants were managed with the regular management practices by the farm services staff at PRC-AAFC. Foliage symptoms, including the emergence rate, symptom type, and symptom development, were recorded twice a week until late August. Tuber symptoms were recorded at harvest and at 2 months post harvest.

ELISA and RT-PCR. ELISA with the PVY ${ }^{\mathrm{O}}$ and PVY ${ }^{\mathrm{N}}$ serotype-specific antibodies MAb2 $\left(\mathrm{PVY}^{\mathrm{O}}\right)$ and 1F5 $\left(\mathrm{PVY}^{\mathrm{N}}\right)$ (Phytodiagnostics) was used to verify the serotypes of the inoculum prior to the mechanical inoculation, whereas ELISA with the serotypenonspecific antibody PVY-Poly (Neogen Europe) was used for the infection experiments. The ELISA was carried out as described previously $(27,29)$ at the Agricultural Certification Services. For the primary infection experiments, leaves located above the inocu-

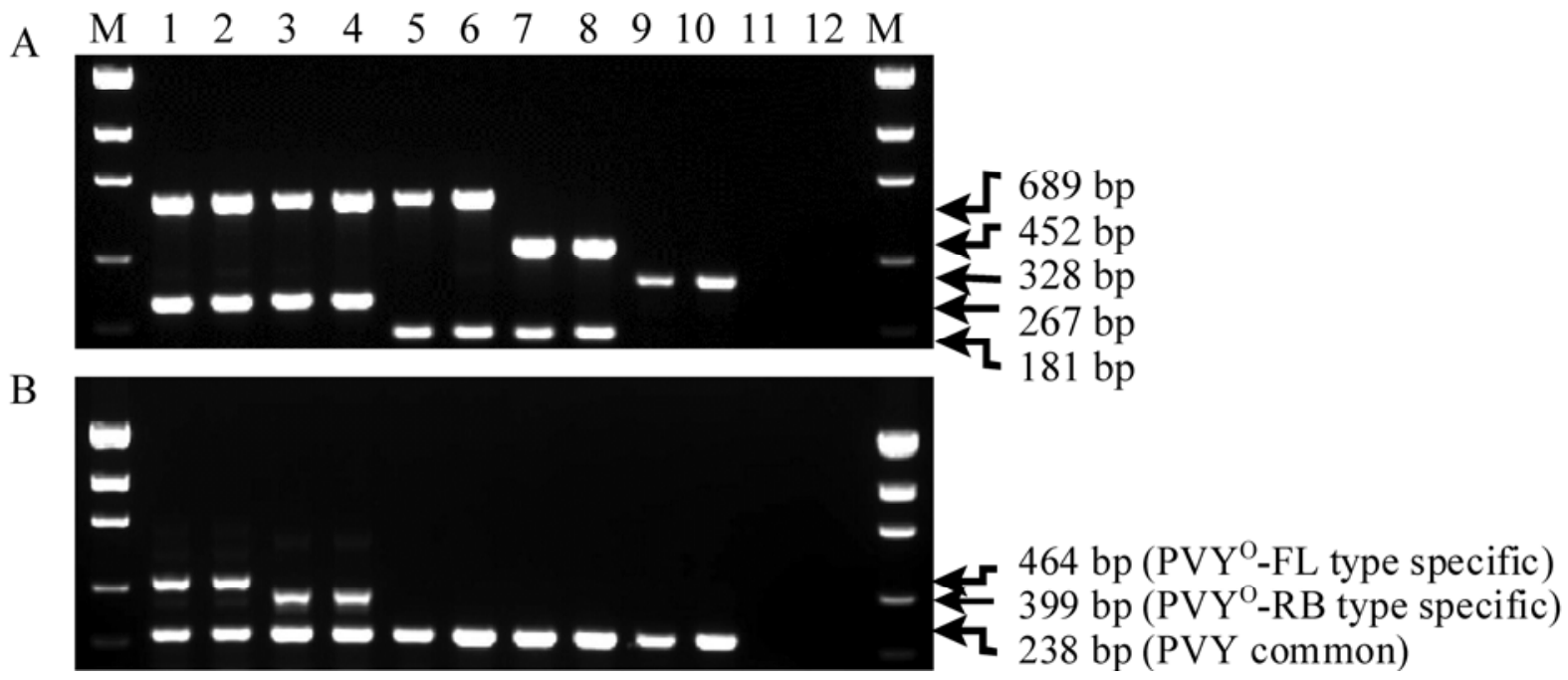

Fig. 1. Genotyping Potato virus $Y(P V Y)$ isolates using reverse-transcription polymerase chain reaction (RT-PCR). A, Multiplex RT-PCR for determination of PVYO, PVYN:O PVYNT, and PVYN strains. B, Multiplex RT-PCR for determination of PVY ${ }^{\circ}$-FL and PVYO-RB isolates. Lanes 1 and 2, PVYO-FL; lanes 3 and 4, PVYO-RB; lanes 5 and 6, PVYN:OMb58; lanes 7 and 8, PVYNTN_Sl; lanes 9 and 10, PVYN-Jg; lanes 11 and12, healthy plant sample; lane M, DNA Ladder (from top to bottom: 2,000, 1,200, 800, 400, and 200 bp). 
lated leaves were sampled at 21 days post inoculation (dpi) and used for ELISA; whereas, for the secondary infection experiments, leaves were sampled at 21 days post plant emergence (dpe) for the ELISA.

Four sets of RT-PCR assays-including the P1-gene-based RTPCR (15), the RJ-based RT-PCR (17), the CP-gene-based PVY ${ }^{\mathrm{O}}$ variant differentiation RT-PCR (14), and the multiplex RT-PCR described by Lorenzen et al. (13)—were used to confirm the PVY isolate or strain purity and identity. Total RNA from leaves located above the inoculated leaves at $28 \mathrm{dpi}$ in the primary infection experiments or from the upper leaves at 30 dpe in the secondary infection experiments was extracted using the sodium sulfite method (30). RT-PCR assays were performed as described in the above-mentioned articles.

\section{Results}

PVY strain or isolate characterization by RT-PCR and ELISA. To reveal the responses of different potato cultivars to different PVY strain groups, 14 potato cultivars and five PVY iso- lates belonging to four strains were used. The isolates were genotyped using P1-gene-based RT-PCR (15) followed by the RJ-based RT-PCR (17) (data not shown). As expected, PVY ${ }^{\mathrm{O}}-\mathrm{FL}$ and PVY ${ }^{\mathrm{O}}$ $\mathrm{RB}$ exhibited a $\mathrm{PVY}{ }^{\mathrm{O}}$-P1 gene and were free of known RJs; $\mathrm{PVY}^{\mathrm{N}: \mathrm{O}}-\mathrm{Mb} 58$ possessed a $\mathrm{PVY}^{\mathrm{N}}-\mathrm{P} 1$ gene and an RJ (RJ1); PVY ${ }^{\mathrm{NTN}}-\mathrm{S} 1$ contained a PVY ${ }^{\mathrm{N}}-\mathrm{P} 1$ gene and three RJs; and $\mathrm{PVY}^{\mathrm{N}}$ $\mathrm{Jg}$, a $\mathrm{PVY}^{\mathrm{N}}$ isolate belonging to the NA-PVY $\mathrm{N}^{\mathrm{N} / \mathrm{NTN}}$ variant group (17), possessed a PVY ${ }^{\mathrm{N}}-\mathrm{P} 1$ gene and was free of the target RJs (data not shown). Further testing of the isolates using the multiplex RT-PCR developed by Lorenzen et al. (13) was consistent with the results (Fig. 1A): the $\mathrm{PVY}^{\mathrm{O}}$ isolates (lanes 1 and 2, $\mathrm{PVY}{ }^{\mathrm{O}}-\mathrm{FL}$; lanes 3 and 4, $\mathrm{PVY}^{\mathrm{O}}$-RB) exhibited a $\mathrm{PVY}^{\mathrm{O}}$-specific banding pattern $(689+267 \mathrm{bp})$, the $\mathrm{PVY}^{\mathrm{N}: \mathrm{O}}-\mathrm{Mb} 58$ (lanes 5 and 6) a $\mathrm{PVY}^{\mathrm{N}: \mathrm{O}}$ banding pattern $(689+181 \mathrm{bp})$, the $\mathrm{PVY}^{\mathrm{NTN}}-\mathrm{Sl}$ (lanes 7 and 8$)$ an Eu-PVY ${ }^{\text {NTN }}$ banding pattern $(452+181 \mathrm{bp})$, and the PVYN-Jg (lanes 9 and 10) a NA-PVY ${ }^{\mathrm{N}}$ banding pattern (328 bp). Further analysis using the $\mathrm{CP}$-gene-based $\mathrm{PVY}^{\mathrm{O}}$ variant analysis (14) showed that the PVYO ${ }^{\mathrm{F} L}$ isolate (Fig. 1B, lanes 1 and 2) possessed a $\mathrm{PVY}{ }^{\mathrm{O}}$-FL/Oz variant-banding pattern $(464+238 \mathrm{bp})$

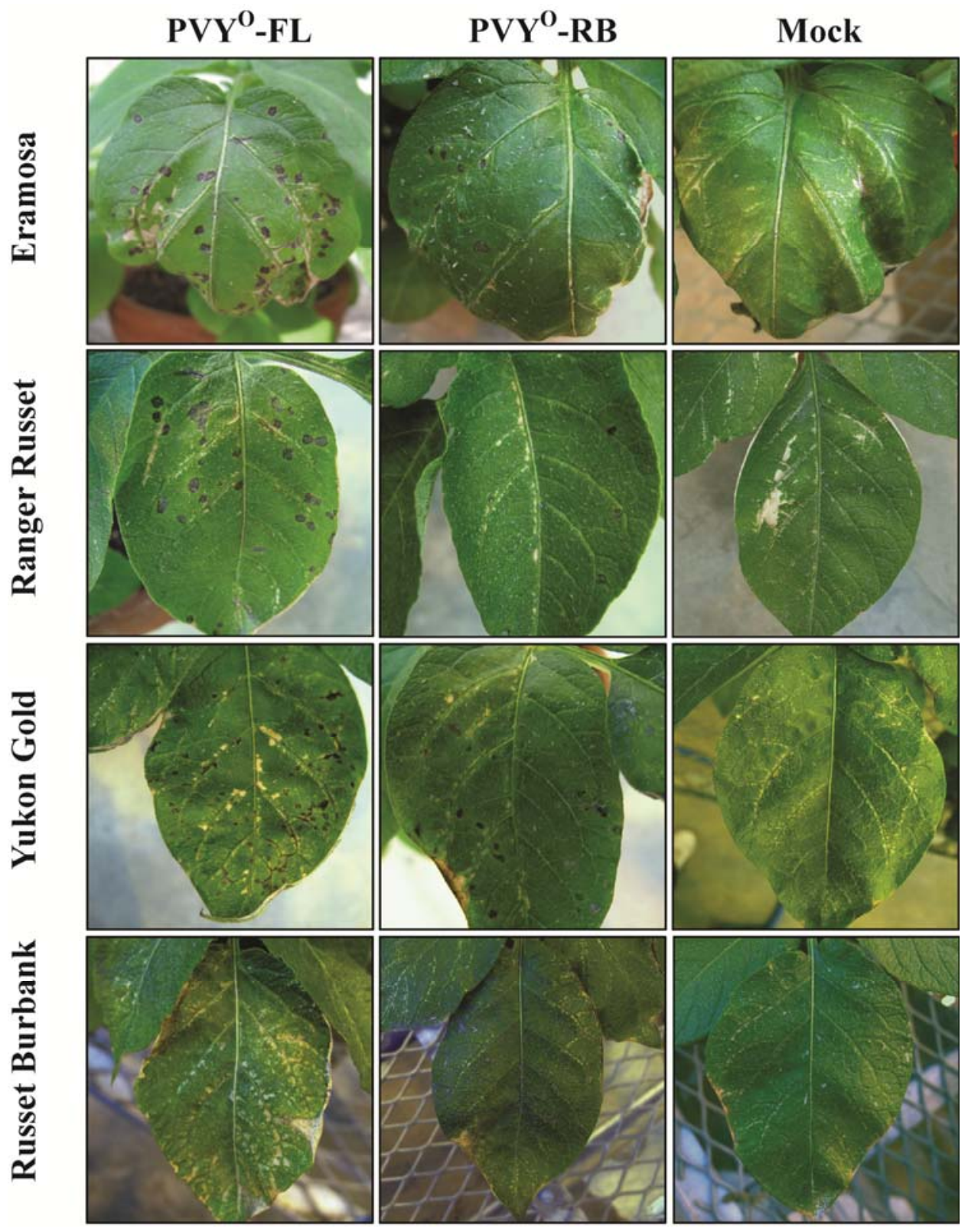

Fig. 2. Local lesions (necrosis) on inoculated leaves in primary infection. Virus-free plantlets of 14 potato cultivars were mechanically inoculated with five Potato virus $Y$ (PVY) isolates belonging to four strains as described in the Materials and Methods. Necrosis was induced by PVYO isolates PVYO-FL and PVYO-RB in seven cultivars, including 'Eramosa', 'Ranger Russet', and 'Yukon Gold'. No visible symptoms were developed in the remaining seven cultivars, including 'Russet Burbank'. Experiments were repeated two times, and similar results were obtained. Pictures shown here were taken 8 days post inoculation in the second repeat. 
whereas the PVY ${ }^{\mathrm{O}}$-RB (Fig. 1B, lanes 3 and 4) exhibited a PVY $\mathrm{P}_{-}$ $\mathrm{RB} / 139$ variant-banding pattern $(399+238 \mathrm{bp})$, consistent with the previous report (14). ELISA analysis using $\mathrm{PVY}^{\mathrm{O}}$ and $\mathrm{PVY}^{\mathrm{N}}$ serotype-specific antibodies MAb2 and 1F5 demonstrated that the $\mathrm{PVY}^{\mathrm{O}}$ and $\mathrm{PVY}^{\mathrm{N}: \mathrm{O}}$ isolates reacted to MAb2 but not $1 \mathrm{~F} 5$ whereas the $\mathrm{PVY}^{\mathrm{N}}$ and Eu-PVY ${ }^{\mathrm{NTN}}$ isolates reacted to the 1F5 but not MAb2 (data not shown), consistent with previous studies $(14,17,18)$. The infection of potato plants with the intended PVY isolates or strains was confirmed by the RT-PCR assays and ELISA analysis in both primary and secondary infection experiments. In addition, no mixed infections were detected from any of the samples.

Symptoms induced by PVY isolates upon mechanical inoculation. Local lesions (LL) on the inoculated leaves were the first visible symptom that occurred at 6 to 8 dpi (Fig. 2). However, LL only developed on AC Chaleur, Eramosa, Goldrush, Jemseg, Ranger Russet, and Yukon Gold inoculated with $\mathrm{PVY}^{\mathrm{O}}$ isolates PVY ${ }^{\mathrm{O}}$-FL and $\mathrm{PVY}{ }^{\mathrm{O}}$-RB. In Katahdin, chlorosis occurred on the inoculated leaves at 5 to $10 \mathrm{dpi}$ and the chlorotic spots then developed into lesions approximately 5 to 10 days later. Comparison of the LL-eliciting abilities of the two $\mathrm{PVY}^{\mathrm{O}}$ isolates revealed that more lesions were incited by $\mathrm{PVY}^{\mathrm{O}}-\mathrm{FL}$ than by $\mathrm{PVY}^{\mathrm{O}}-\mathrm{RB}$ in all the above cultivars (Fig. 2). The average numbers of LL per plant elicited by $\mathrm{PVY}{ }^{\mathrm{O}}$-FL versus $\mathrm{PVY} \mathrm{O}^{\mathrm{O}} \mathrm{RB}$ at 8 dpi in different cultivars in one of the two repeated experiments were AC Chaleur, 36.0 versus 14.0; Eramosa, 120.0 versus 38.5; Goldrush, 62.0 versus 33.0; Jemseg, 64.5 versus 32.5; Ranger Russet, 101.3 versus 51.3; and Yukon Gold, 89.0 versus 58.5. Although not counted, a similar trend was observed in the other repeat.
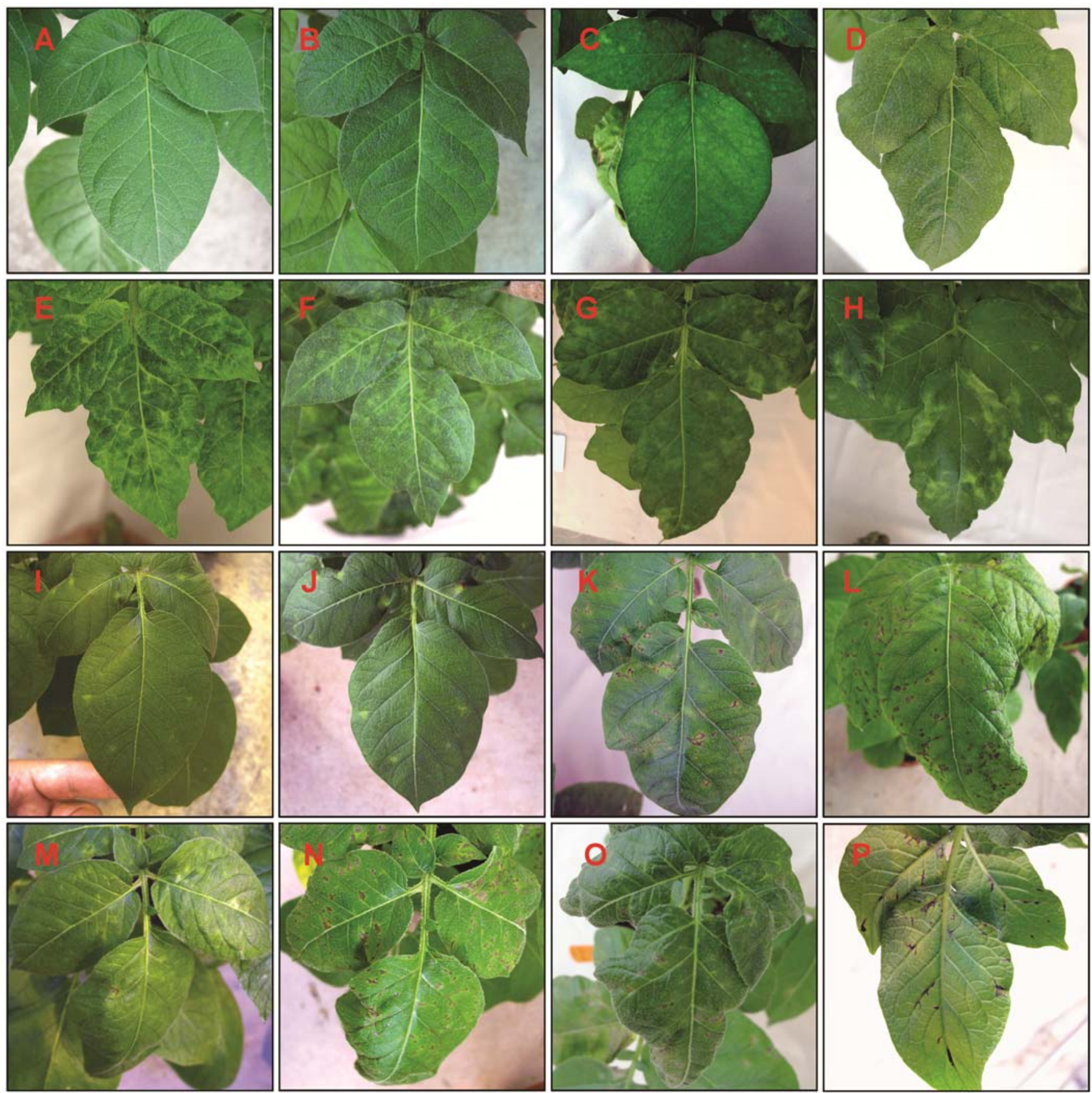

Fig. 3. Systemic symptoms caused by various Potato virus $Y(P V Y)$ isolates on latterly emerged uninoculated leaves of potato plants of different cultivars in primary infection A, Mock, 'Jemseg' (13 days post inoculation [dpi]). B, PVYN-Jg, Jemseg (18 dpi). C, PVYNTN-SI, 'Eramosa' (21 dpi). D, PVYN:O-Mb58, 'Katahdin' (21 dpi). E, PVYO-FL, 'Goldrush' (25 dpi). F, PVYN:O-Mb58, Goldrush (40 dpi). G, PVYN:O-Mb58, Eramosa (31 dpi). H, PVYN:O-Mb58, Eramosa (40 dpi). I-K, PVYO-RB, Jemseg at 15 (I), 18 (J), and 21 (K) dpi. L, PVYO-FL, 'Yukon Gold' (18 dpi). M-O, PVYO-FL, Jemseg at 15 (M), 18 (N), and 21 (O) dpi. P, PVYO-FL, 'Cherokee' (13 dpi). Experiments were repeated two times, and similar results were obtained. Pictures shown here were taken from the third leaf from the top of an inoculated plant in the second repeated experiment. 
Systemic symptoms occurred on latterly emerged leaves and whole plants. Systemic symptoms varied, depending on the potato cultivars and PVY strains or isolates. Generally, two main types of symptoms (namely, mosaic and necrosis) were observed. The mosaic type of responses included symptoms ranging from symptomless to varying degrees of mosaic (Fig. 3B-H), leaf rugosity (Fig. 3D-H), and leaf deformation (Fig. 3D-H). The necrotic type of responses included systemic necrotic spots (Fig. 3L) and veinal necrotic streak (Fig. 3P). The necrotic responses were often followed by rapid aging, leaf drop (Fig. 4, top panel, PVY ${ }^{\mathrm{O}}$-FL), leaf death (Fig. 4, top panel, PVY ${ }_{-}$FL and $\mathrm{PVY}^{\mathrm{NTN}}-\mathrm{Sl}$ ), and, sometimes, premature death of the whole plant (Table 1). Chlorotic spots (Fig. 3, I, J, and M) were also observed in some cultivars, such as Jemseg infected with $\mathrm{PVY}^{\mathrm{O}}$ isolates. The chlorotic spots further developed into necrotic spots (Fig. 3, K, N, and O). The detailed responses of the potato cultivars to PVY isolates are summarized in Table 1. Red LaSoda did not develop obvious symptoms upon infection with any of the five tested PVY isolates; CalWhite and La Rouge developed very mild mosaic upon infection with $\mathrm{PVY} \mathrm{Y}^{\mathrm{O}}-\mathrm{FL}, \mathrm{PV} \mathrm{Y}^{\mathrm{O}}-\mathrm{RB}, \mathrm{PVY}^{\mathrm{N}: \mathrm{O}}$, or PVY ${ }^{\mathrm{NTN}}$. Russet Burbank developed mild mosaic to $\mathrm{PVY}^{\mathrm{O}}$ isolates but not to $\mathrm{PVY}^{\mathrm{N}: \mathrm{O}}$, $\mathrm{PVY}^{\mathrm{NTN}}$, or PVY ${ }^{\mathrm{N}}$; and Russet Norkotah developed only mild mosaic in response to all isolates tested.

$\mathrm{PVY}^{\mathrm{O}}$ generally incited more severe symptoms than other PVY strains on most cultivars. AC Chaleur, Cherokee, Eramosa, Goldrush, Jemseg, Katahdin, Ranger Russet, and Yukon Gold developed systemic necrosis and leaf drop at 12 to 18 and 22 to 34 dpi, respectively. Further comparison revealed that the development of systemic necrosis and leaf drop in PVY ${ }^{\mathrm{O}}$-FL-infected plants was at least 3 to 5 days ahead of $\mathrm{PVY}^{\mathrm{O}}-\mathrm{RB}$-infected plants in these cultivars (Fig. 3I-K and $\mathrm{M}-\mathrm{O}$ ). Moreover, the symptoms in $\mathrm{PVY}^{\mathrm{O}}$-FL-infected plants were more severe than $\mathrm{PVY}^{\mathrm{O}}$-RBinfected plants, as demonstrated in Yukon Gold (Fig. 4) and Jemseg (Supplementary Figure S1). Premature death occurred in AC Chaleur, Eramosa, Jemseg, and Ranger Russet inoculated with $\mathrm{PVY}^{\mathrm{O}}$-FL at 35 to $41 \mathrm{dpi}$ (Table 1).

Although PVY ${ }^{\mathrm{NTN}}$ did not incite LL on any of the tested cultivars, systemic necrosis and mid-leaf drop did occur in PVY $\mathrm{NTN}_{-}$ infected AC Chaleur, Cherokee, and Yukon Gold plants. PVY ${ }^{\mathrm{N}: \mathrm{O}_{-}}$ $\mathrm{Mb} 58$ and $\mathrm{PVY}^{\mathrm{N}}$-Jg did not induce necrotic reactions in any of the cultivars (Table 1). PVYN induced very mild symptoms, mainly mild mosaic, that were not always visually recognizable in most of the tested cultivars, while PVY ${ }^{\mathrm{N}: \mathrm{O}}$ caused mild to severe mosaic symptoms (Table 1; Fig. 4) in most of the tested cultivars.

It is interesting to note that tubers of $\mathrm{PVY}^{\mathrm{NTN}}$-infected $\mathrm{AC}$ Chaleur, Cherokee, and Yukon Gold plants, which exhibited a certain degree of systemic foliage necrosis, developed necrotic ringspots (Fig. 4; Supplementary Figure S2). Surprisingly, necrotic ringspots were also observed in tubers of Cherokee plants infected with PVY ${ }^{\mathrm{N}}-\mathrm{Jg}$.

A preliminary evaluation of yield loss was carried out for each PVY isolate in one of the two repeats (Supplementary Table S1). In comparison with uninoculated (mock) plants, PVY ${ }^{\mathrm{O}}$-FL, PVY ${ }^{\mathrm{O}}$, $\mathrm{PVY}^{\mathrm{O}}-\mathrm{RB}$, and $\mathrm{PVY} \mathrm{YTN}_{-}^{\mathrm{N}} \mathrm{Sl}$ caused higher yield loss, on average,

Table 1. Foliage symptoms of 14 potato cultivars in response to five Potato virus $Y$ (PVY) isolates in primary infection in the greenhouse ${ }^{\mathrm{a}}$

\begin{tabular}{|c|c|c|c|c|c|c|c|c|c|c|}
\hline \multirow[b]{2}{*}{ Cultivars } & \multicolumn{2}{|c|}{ PVYO $-F L$} & \multicolumn{2}{|c|}{ PVY'-RB } & \multicolumn{2}{|c|}{ PVYN:O-Mb58 } & \multicolumn{2}{|c|}{ PVY $^{\text {NTN_SI }}$} & \multicolumn{2}{|c|}{ PVYN-Jg } \\
\hline & $21 \mathrm{dpi}$ & 35 dpi & $21 \mathrm{dpi}$ & 35 dpi & 21 dpi & 35 dpi & 21 dpi & 35 dpi & 21 dpi & 35 dpi \\
\hline AC Chaleur & LL sN & sN sLD sDF & LL & $\mathrm{sN}$ mLD sDF & $\mathrm{mM}$ & $\mathrm{mM}$ & sM & $\mathrm{mN}$ & - & - \\
\hline CalWhite & - & $\mathrm{mM}$ & - & - & - & $\mathrm{mM}$ & - & $\mathrm{mM}$ & _- & - \\
\hline Cherokee & $\mathrm{mN}$ & $\mathrm{mM}$ sLD sDF & $\mathrm{mN}$ & $\mathrm{mM}$ sLD sDF & $\mathrm{mM}$ & sM & $\mathrm{mN}$ & $\mathrm{mLD} \mathrm{mDF}$ & $\mathrm{mM}$ & - \\
\hline Eramosa & LL sN & sLD sDF PD & LL sN & sLD sDF PD & sM & $\mathrm{sM} \mathrm{mDF}$ & sM & $\mathrm{sM} \mathrm{mDF}$ & $\mathrm{mM}$ & $\mathrm{mM}$ \\
\hline Glodrush & LL sN & $\mathrm{sM}$ sLD mDF & LL sN & $\mathrm{sM} \mathrm{mLD} \mathrm{mDF}$ & sM & sM & $\mathrm{mM}$ & $\mathrm{mM}$ & $\mathrm{mM}$ & - \\
\hline Jemseg & LL sN & PD & LL sN & sN sLD mDF & $\mathrm{mM}$ & $\mathrm{sM}$ & $\mathrm{mM}$ & $\mathrm{mM}$ & $\mathrm{mM}$ & $\mathrm{mM}$ \\
\hline Katahdin & $\mathrm{mN}$ & $\mathrm{mN} \mathrm{mLD} \mathrm{mDF}$ & $\mathrm{mM}$ & $\mathrm{mN}$ & $\mathrm{mM}$ & $\mathrm{mM}$ & - & - & - & - \\
\hline La Rouge & - & $\mathrm{mM} \mathrm{mDF}$ & - & $\mathrm{mDF}$ & - & $\mathrm{mM}$ & - & - & - & - \\
\hline Ranger Russet & LL sN & PD & LL sN & $\mathrm{sN}$ sLD mDF & $\mathrm{mM}$ & $\mathrm{sM}$ & $\mathrm{mM}$ & $\mathrm{mM}$ & _- & - \\
\hline Red LaSoda & - & - & - & - & - & - & - & - & - & - \\
\hline Russet Burbank & $\mathrm{mM}$ & $\mathrm{mM}$ & $\mathrm{mM}$ & $\mathrm{mM}$ & _- & - & - & _- & - & - \\
\hline Russet Norkotah & $\mathrm{mM}$ & $\mathrm{mM}$ & $\mathrm{mM}$ & $\mathrm{mM}$ & $\mathrm{mM}$ & $\mathrm{mM}$ & $\mathrm{mM}$ & $\mathrm{mM}$ & - & $\mathrm{mM}$ \\
\hline Superior & $\mathrm{mM}$ & $\mathrm{sM} \mathrm{mDF}$ & $\mathrm{mM}$ & $\mathrm{mM} \mathrm{mDF}$ & $\mathrm{mM}$ & $\mathrm{sM} \mathrm{mDF}$ & $\mathrm{mM}$ & $\mathrm{mM} \mathrm{mDF}$ & - & - \\
\hline Yukon Gold & LL sN & sN sLD sDF & LL & $\mathrm{sN}$ sLD mDF & - & - & $\mathrm{mN}$ & $\mathrm{mN} \mathrm{mLD} \mathrm{mDF}$ & - & - \\
\hline
\end{tabular}

a Abbreviations: dpi, days post inoculation; -, no visible symptoms; LL, local lesion; N, necrosis; M, mosaic; LD, leaf drop/death; DF, leaf deformation; PD, premature plant death; $\mathrm{m}$, mild; $\mathrm{s}$, severe. The primary infection experiments were repeated two times in the greenhouse and similar foliage symptoms were observed in the same cultivar and isolate combination. Results of the second experiment are presented.

Table 2. Foliage symptoms of 14 potato cultivars in response to five Potato virus $Y$ (PVY) isolates in secondary infection in the greenhouse ${ }^{\mathrm{a}}$

\begin{tabular}{|c|c|c|c|c|c|c|c|c|c|c|}
\hline \multirow[b]{2}{*}{ Cultivars } & \multicolumn{2}{|c|}{ PVYO-FL } & \multicolumn{2}{|c|}{ PVYO-RB } & \multicolumn{2}{|c|}{ PVYN:O-Mb58 } & \multicolumn{2}{|c|}{ PVYYNN_SI $^{N^{N}}$} & \multicolumn{2}{|c|}{ PVYN-Jg } \\
\hline & 21 dpe & 49 dpe & 21 dpe & 49 dpe & 21 dpe & 49 dpe & 21 dpe & 49 dpe & 21 dpe & 49 dpe \\
\hline AC Chaleur & sN sLD sDF & PD & $\mathrm{mN} \mathrm{mDF}$ & sN sLD & $\mathrm{mM}$ & m-sM & - & $\mathrm{mM} \mathrm{mDF}$ & - & - \\
\hline CalWhite & $\mathrm{mM}$ & - & $\mathrm{mM}$ & - & $\mathrm{mM}$ & $\mathrm{mM}$ & $\mathrm{mM}$ & - & - & - \\
\hline Cherokee & $\mathrm{mN} \mathrm{mLD} \mathrm{sDF}$ & mN sLD sDF & $\mathrm{mN}$ mLD sDF & $\mathrm{mN}$ sLD sDF & $\mathrm{sM} \mathrm{mDF}$ & $\mathrm{sM} \mathrm{sDF}$ & $\mathrm{mM} \mathrm{mDF}$ & $\mathrm{sM} \mathrm{sDF} \mathrm{mN}$ & $\mathrm{mN}$ & $\mathrm{mM} \mathrm{mDF}$ \\
\hline Eramosa & sN mLD sDF & sN mLD sDF & $\mathrm{sN}$ mLD & sN sLD sDF & $\mathrm{sM}$ & $\mathrm{sM}$ & $\mathrm{mM}$ & sM & - & $\mathrm{mM}$ \\
\hline Goldrush & $\mathrm{mN} \mathrm{mLD} \mathrm{sDF}$ & $\mathrm{mN} \mathrm{mLD} \mathrm{sDF}$ & $\mathrm{mN} \mathrm{mLD} \mathrm{mDF}$ & $\mathrm{mN} \mathrm{mLD} \mathrm{mDF}$ & sM & $\mathrm{m}$-sM mDF & - & $\mathrm{sM} \mathrm{mDF}$ & - & $\mathrm{mM}$ \\
\hline Jemseg & sN sLD sDF & PD & $\mathrm{sN}$ mLD mDF & $\mathrm{sN}$ sLD mDF PD & $\mathrm{sM}$ & $\mathrm{sM}$ & $\mathrm{mM}$ & $\mathrm{sM}$ & $\mathrm{mM}$ & $\mathrm{m}-\mathrm{sM}$ \\
\hline Katahdin & $\mathrm{mN}$ mLD sDF & $\mathrm{mN}$ sLD mDF & $\mathrm{mDF}$ & $\mathrm{mN} \mathrm{mLD} \mathrm{mDF}$ & $\mathrm{mM}$ & $\mathrm{sM}$ & $\mathrm{mM}$ & sM & - & $\mathrm{mM}$ \\
\hline La Rouge & $\mathrm{mM} \mathrm{mDF}$ & m-sM mDF & - & $\mathrm{mM}$ & - & $\mathrm{m}$-sM mDF & $\mathrm{mM}$ & $\mathrm{mM}$ & - & $\mathrm{mM}$ \\
\hline Ranger Russet & sN sLD sDF & PD & $\mathrm{mN}$ sLD sDF & PD & $\mathrm{mM}$ & $\mathrm{sM}$ & $\mathrm{mM}$ & sM & - & $\mathrm{mM}$ \\
\hline Red LaSoda & $\mathrm{mM} \mathrm{mDF}$ & $\mathrm{mM} \mathrm{mDF}$ & $\mathrm{mM} \mathrm{mDF}$ & $\mathrm{mM}$ & $\mathrm{mM}$ & $\mathrm{mM}$ & $\mathrm{mM}$ & $\mathrm{mM}$ & - & $\mathrm{mM}$ \\
\hline Russet Norkotah & - & sM & - & m-sM & $\mathrm{mM}$ & $\mathrm{m}-\mathrm{sM}$ & - & sM & - & $\mathrm{mM}$ \\
\hline Russet Burbank & $\mathrm{mM} \mathrm{mDF}$ & $\mathrm{m}$-sM & $\mathrm{mM} \mathrm{mDF}$ & $\mathrm{mM}$ & $\mathrm{mM}$ & - & $\mathrm{mM}$ & - & - & - \\
\hline Superior & $\mathrm{sM}$ & $\mathrm{sM} \mathrm{mDF}$ & $\mathrm{mM}$ & $\mathrm{mM}$ & sM & $\mathrm{sM} \mathrm{mDF}$ & - & $\mathrm{sM}$ mDF & - & $\mathrm{mM}$ \\
\hline Yukon Gold & $\mathrm{mN} \mathrm{mLD} \mathrm{mDF}$ & sN sLD sDF & $\mathrm{mN}$ & $\mathrm{sN}$ sLD mDF & - & $\mathrm{mM}$ & $\mathrm{mM}$ & m-sM mDF & - & - \\
\hline
\end{tabular}

${ }^{a}$ Abbreviations: dpe, days post plant emergence; -, no visible symptoms; LL, local lesion; N, necrosis; M, mosaic; LD, leaf drop/death; DF, leaf deformation; PD, premature plant death; $\mathrm{m}$, mild; s, severe. The secondary infection experiments were repeated two times in the greenhouse and similar foliage symptoms were observed in the same cultivar and isolate combination. Results of the second experiment are presented. 
than $\mathrm{PVY}^{\mathrm{N}: \mathrm{O}}-\mathrm{Mb} 58$ and $\mathrm{PVY}^{\mathrm{N}}-\mathrm{Jg}$ in 14 potato cultivars tested in this study. This was associated with the severity of symptoms caused in primary infections and may have contributed to higher yield loss that occurred in necrotic-type responses caused by these $\mathrm{PVY}$ isolates than mosaic ones.

Effects of secondary infection with PVY isolates on symptom expression in potato cultivars in the greenhouse and the field. To determine whether secondary (tuber-borne) PVY infection exhibits symptomatology similar to that of primary infection, progeny tubers of the PVY-infected plants were planted in the greenhouse and the field. Overall, the symptoms resembled those of the primary infection for the respective cultivar and strain or isolate combinations (Tables 2 and 3; Fig. 4; Supplementary Figures S1S4). Necrotic type responses in current-season-infected plants always resulted in similar responses in the progeny plants whereas the mosaic type of responses in the primarily infected plants resulted in mosaic type of reactions in the daughter plants. Nevertheless, the symptoms were usually more obvious or more severe in plants with the secondary infection. For instance, CalWhite, which was nearly symptomless in primary infections (Table 1), developed mild but obvious mosaic with all PVY isolates except PVY $^{N_{-}}$Jg in secondary infections (Fig. 5). The same trend was true for Red LaSoda, Russet Norkotah, and Russet Burbank (Table 2). In cultivars (e.g., Jemseg, Eramosa, Ranger Russet, Yukon Gold, and AC Chaleur) exhibiting necrotic responses to $\mathrm{PVY}^{\mathrm{O}}$ infection, more visible severe leaf deformation, systemic necrosis, leaf drop, and premature plant death were observed in the secondary infection (Tables 2 and 3). Similar to the primary infection, PVY ${ }^{\mathrm{O}}$-FL incited more severe foliage symptoms in secondarily infected plants than PVYO-RB in these cultivars, as shown in Yukon Gold (Fig. 4) and Jemseg. In the field trial, similar trends were observed in all cultivars infected with the respective PVY isolates (Table 3). It is particularly noteworthy that $\mathrm{PVY}^{\mathrm{N}}$-Jg incited noticeable symptoms, although relatively mild, on most cultivars under the field conditions at 55 dpe (Table 3). PTNRD was observed in both primary and secondary infections in AC Chaleur, Yukon Gold, Cherokee with PVY ${ }^{\mathrm{NTN}}$, and Cherokee with $\mathrm{PVY}^{\mathrm{N}}$-Jg (Fig. 4) under both greenhouse and field conditions, demonstrating that PTNRD could be induced in both current-season and tuber-borne infections.

A similar trend in yield reduction caused by various PVY isolates was observed in secondary infections. No tubers were produced in AC Chaleur, Jemseg, and Ranger Russet infected with $\mathrm{PVY}^{\mathrm{O}}$-FL or Ranger Russet infected with $\mathrm{PVY}^{\mathrm{O}}-\mathrm{RB}$ due to early premature plant death (Table 2; Supplementary Table S2). Overall, losses from secondary infections were greater than those observed in plants with primary infections. Nevertheless, the yield reduction of tuber-borne infection with $\mathrm{PVY}^{\mathrm{N}: \mathrm{O}}-\mathrm{Mb} 58, \mathrm{PVY}^{\mathrm{NTN}}-\mathrm{Sl}$, and $\mathrm{PVY}^{\mathrm{N}}-\mathrm{Jg}$ was comparable with that in the primary infections.

\section{Discussion}

A wide range of responses has been described in host plants in reaction to PVY infection $(24,26)$. Using five PVY isolates belonging to four strains and 14 commonly grown potato cultivars, diverse responses of potato to PVY infection were observed in this study. Clearly, the type and severity of responses were determined by potato cultivar and PVY strain or isolate, and were affected by whether the infection was primary or secondary. In spite of considerable differences in symptom expression among potato cultivars, $\mathrm{PVY}^{\mathrm{O}}$ was the most severe strain overall, followed by $\mathrm{PVY}^{\mathrm{NTN}}, \mathrm{PVY}^{\mathrm{N}: \mathrm{O}}$, and $\mathrm{PVY}^{\mathrm{N}}$. This was particularly true for the cultivars showing necrotic responses to $\mathrm{PVY}^{\mathrm{O}}$. Among the two $\mathrm{PVY}^{\mathrm{O}}$ isolates, $\mathrm{PVY}{ }^{\mathrm{O}}$-FL induced more severe symptoms than PVY ${ }^{\mathrm{O}}-\mathrm{RB}$, consistent with previous studies (14), and demonstrating $\mathrm{PVY}^{\mathrm{O}}-\mathrm{FL}$ as a severe variant of $\mathrm{PVY}^{\mathrm{O}}$. Despite systemic foliage necrosis in AC Chaleur, Cherokee, Eramosa, Goldrush, Jemseg, Katahdin, Ranger Russet, and Yukon Gold infected with PVY ${ }^{\mathrm{O}}$, progeny tubers did not develop any visible necrosis, indicating that the foliage necrosis was not associated with tuber necrosis. Like PVY ${ }^{\mathrm{O}}-\mathrm{FL}$ and $\mathrm{PVY} \mathrm{O}_{-}^{\mathrm{O} B}, \mathrm{PVY}^{\mathrm{NTN}}-\mathrm{S} 1$ incited systemic foliage necrosis on AC Chaleur, Cherokee, and Yukon Gold. It is interesting to note that tuber necrotic ringspots, or PTNRD, were also induced in these cultivars by $\mathrm{PVY}^{\mathrm{NTN}}$-Sl, suggesting a correlation between the foliage necrosis and PTNRD in infections by PVY ${ }^{\mathrm{NTN}}$. The PVY ${ }^{\mathrm{N}}$ isolate $\mathrm{PVY}^{\mathrm{N}}-\mathrm{Jg}$, an NA-type of PVY ${ }^{\mathrm{N}}$, induced mild foliage symptoms ranging from symptomless to mild mosaic in most cultivars. However, this isolate induced PTNRD on Cherokee. Previously, PVY ${ }^{\text {NTN }}-\mathrm{Tu} 660$, an NA-PVY ${ }^{\mathrm{NTN}}$ or nonrecombinant PVY ${ }^{\mathrm{NTN}}$, was found to be capable of induction of PTNRD in 'Norchip' and Ranger Russet, whereas PVY ${ }^{\mathrm{N}}-\mathrm{Jg}$ failed to do so (16). In addition to PVY ${ }^{\mathrm{NTN}}$ (both recombinant and nonrecombinant), isolates genetically belonging to $\mathrm{PVY}^{\mathrm{N}: \mathrm{O}} / \mathrm{PVY}^{\mathrm{N}-\mathrm{Wi}}$ and $\mathrm{PVY}^{\mathrm{O}}$ have been reported to induce PTNRD $(7,21)$. Therefore, it is not surprising that PVY ${ }^{\mathrm{N}}-\mathrm{Jg}$ induced PTNRD in Cherokee, one of the PVY ${ }^{\mathrm{NTN}}$-susceptible cultivars, in this study. Unlike PVY ${ }^{\mathrm{N}}-\mathrm{Jg}$ and $\mathrm{PVY}^{\mathrm{NTN}}-\mathrm{Sl}, \mathrm{PVY}^{\mathrm{N}: \mathrm{O}}-\mathrm{Mb} 58$, a severe PVY ${ }^{\mathrm{N}: \mathrm{O}}$ isolate on tobacco (18), did not cause any visible PTNRD on the tested cultivars, whereas it caused mosaic ranging from mild to severe on the cultivars.

Studies have demonstrated that the symptom intensity of PVYinfected plants of potato cultivars is not a reliable indicator for yield loss $(8,23)$, and high yield loss has been reported in some cultivars with mild symptoms upon PVY infection (20). In this study, the potential impact of PVY isolates on the yield of potato cultivars was assessed in the potted plants in the greenhouse. As expected, the cultivars that exhibited necrotic responses to $\mathrm{PVY}$ resulted in greater yield reduction when they contracted the iso-

Table 3. Field foliage symptoms of 14 potato cultivars in response to five Potato virus $Y$ (PVY) isolates in secondary infection in field ${ }^{\text {a }}$

\begin{tabular}{|c|c|c|c|c|c|c|c|c|c|c|}
\hline \multirow[b]{2}{*}{ Cultivars } & \multicolumn{2}{|c|}{ PVY'-FL } & \multicolumn{2}{|c|}{ PVYO-RB } & \multicolumn{2}{|c|}{ PVYN:O-Mb58 } & \multicolumn{2}{|c|}{ PVYNTN_Sl } & \multicolumn{2}{|c|}{ PVYN-Jg } \\
\hline & 25 dpe & 55 dpe & 25 dpe & 55 dpe & 25 dpe & 55 dpe & 25 dpe & 55 dpe & 25 dpe & 55 dpe \\
\hline AC Chaleur & DF sN sLD & sN sLD PD & sN LD & $\mathrm{mM}$ LD & $\mathrm{mM}$ & sM & $\mathrm{mM}$ & $\mathrm{mDF} M$ & $\mathrm{mM}$ & $\mathrm{mM}$ \\
\hline CalWhite & $\mathrm{mM}$ & $\mathrm{mM}$ & $\mathrm{mM}$ & m-sM & M & $\mathrm{sM}$ & $\mathrm{mM}$ & sM & - & - \\
\hline Cherokee & sN LD & sN sLD PD & sN LD & sN sLD PD & $\mathrm{mM}$ & $\mathrm{mDF} \mathrm{sM}$ & $\mathrm{mM}$ & mDF m-sM & $\mathrm{mM} \mathrm{DF}$ & DF \\
\hline Eramosa & sN sLD & $\mathrm{PD}$ & $\mathrm{sN}$ mLD & sN LD & $\mathrm{mM}$ & sM & $\mathrm{mM}$ & sM & - & - \\
\hline Glodrush & sN LD & sDF sN mLD & sN LD & sDF sN mLD & $\mathrm{mM}$ & $\mathrm{sM}$ & $\mathrm{mM}$ & sM & - & $\mathrm{mM}$ \\
\hline Jemseg & DF LD sN & $\mathrm{PD}$ & sN LD & sN sLD & $\mathrm{mM}$ & m-sM & $\mathrm{mM}$ & $\mathrm{sM}$ & - & $\mathrm{mM}$ \\
\hline Katahdin & sN sLD DF & sN mLD PD & sN LD & sN sLD & $\mathrm{mM}$ & $\mathrm{sM}$ & $\mathrm{mM}$ & sM & - & $\mathrm{mM}$ \\
\hline La Rouge & $\mathrm{mM} \mathrm{mLD} \mathrm{mDF}$ & $\mathrm{mDF} \mathrm{mN} \mathrm{sM}$ & $\mathrm{mM}$ & $\mathrm{mDF} \mathrm{mN} \mathrm{sM}$ & $\mathrm{mM}$ & $\mathrm{mM}$ & $\mathrm{mM}$ & $\mathrm{mM}$ & - & - \\
\hline Ranger Russet & sN LD & sN sLD PD & sN LD & sN sLD PD & $\mathrm{mM}$ & $\mathrm{m}$-sM & $\mathrm{mM}$ & $\mathrm{m}$-sM & - & $\mathrm{mM}$ \\
\hline Red LaSoda & $\mathrm{mM}$ & $\mathrm{mDF} \mathrm{mN}$ & $\mathrm{mM}$ & $\mathrm{mDF} \mathrm{mN}$ & $\mathrm{mM}$ & m-sM & $\mathrm{mM}$ & m-sM & - & $\mathrm{mM}$ \\
\hline Russet Burbank & $\mathrm{mM}$ & m-sM & $\mathrm{mM}$ & m-sM & $\mathrm{mM}$ & m-sM & $\mathrm{mM}$ & m-sM & - & $\mathrm{mM}$ \\
\hline Russet Norkotah & $\mathrm{mM}$ & $\mathrm{mM}$ & $\mathrm{mM}$ & $\mathrm{mM}$ & $\mathrm{mM}$ & $\mathrm{mM}$ & $\mathrm{mM}$ & $\mathrm{mM}$ & - & $\mathrm{mM}$ \\
\hline Superior & $\mathrm{mM}$ & $\mathrm{mDF} \mathrm{mM}$ & $\mathrm{mM}$ & $\mathrm{mDF}$ m-sM & $\mathrm{mM}$ & m-sM & $\mathrm{mM}$ & m-sM & $\mathrm{mM}$ & $\mathrm{mM}$ \\
\hline Yukon Gold & sLD sN & $\mathrm{PD}$ & sN sLD & sN sLD & $\mathrm{mM}$ & m-sM & $\mathrm{mM}$ & $\mathrm{m}-\mathrm{sN}$ & $\mathrm{mM}$ & m-sM \\
\hline
\end{tabular}

a Abbreviations: dpe, days post plant emergence; -, no visible symptoms; LL, local lesion; N, necrosis; M, mosaic; LD, leaf drop/death; DF, leaf deformation; PD, premature plant death; m, mild; s, severe; dpe, days post plant emergence. The secondary infection experiments in field were repeated in the 2010 and 2011 growing seasons and similar foliage symptoms were observed in the same cultivar and isolate combination. Results of 2010 are presented. 

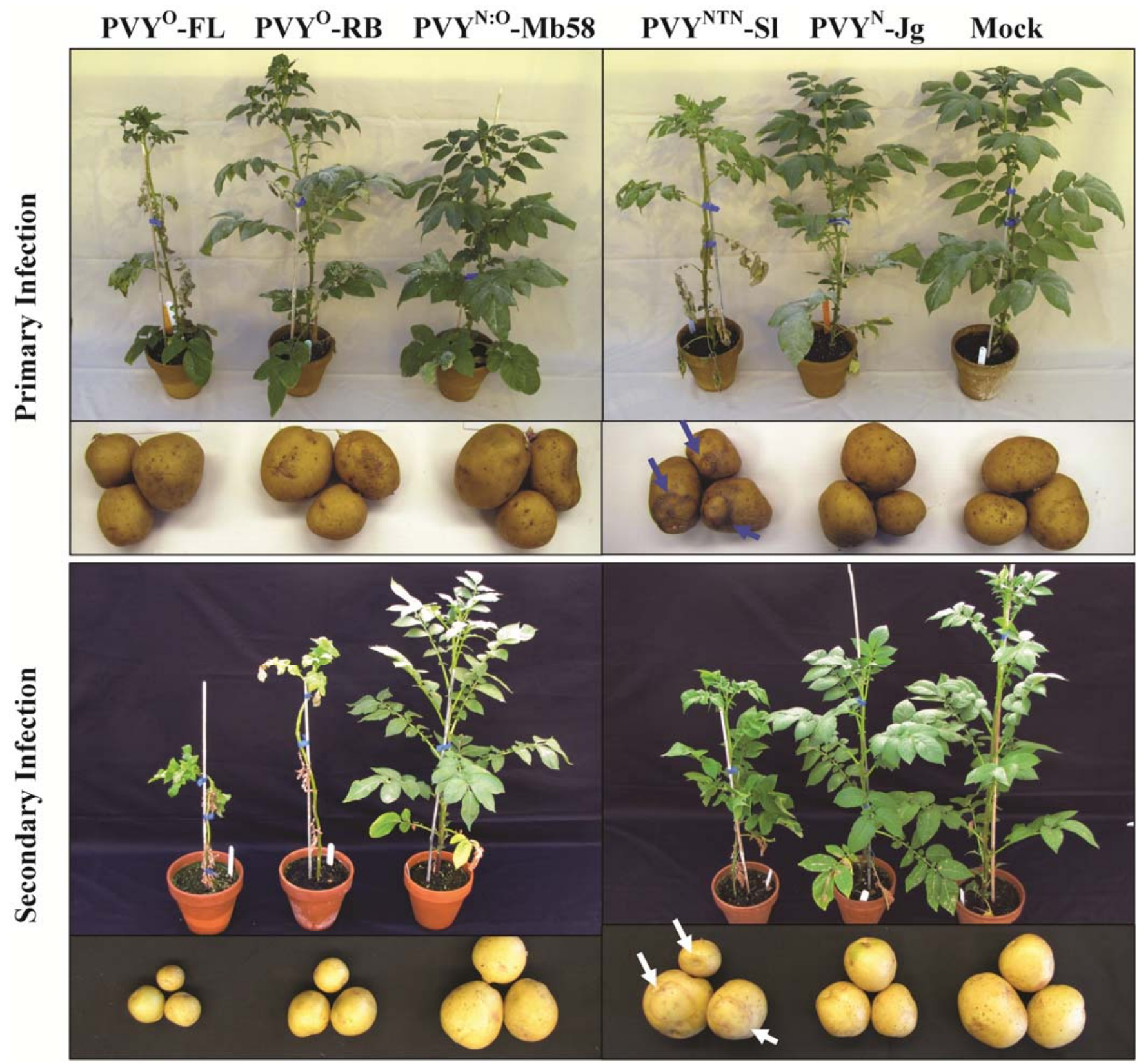

Fig. 4. Foliage and tuber symptoms on 'Yukon Gold' in the primary and secondary infections with Potato virus $Y(P V Y)$ isolates in the greenhouse. In primary infection panels, plants at 31 days post inoculation and tubers at 4 months post harvest are shown. In secondary infection panels, plants at 60 days post emergence and tubers at 1 month post harvest are shown. Necrotic ringspots on tubers are indicated by arrows. Both experiments were repeated two times, and similar results were obtained each time. Pictures shown were taken from the second repeat of respective infection experiments.

lates (e.g., PVYO $-F L, \mathrm{PVY}^{\mathrm{O}}-\mathrm{RB}$, and $\mathrm{PVY}^{\mathrm{NTN}}-\mathrm{Sl}$ ) that were capable of induction of necrosis over isolates (e.g., PVY $\mathrm{PV}_{-} \mathrm{Jg}$ and $\mathrm{PVY}^{\mathrm{N}: \mathrm{O}}$ ) that only incited mosaic reactions at an early stage of plant growth. Nevertheless, for cultivars that only developed mosaic-type reactions to all isolates, a yield reduction up to $46.1 \%$ was observed in primary infections. Undoubtedly, these results should only be used as a preliminary assessment for the potential impact on yield by PVY isolates or strains, and more refined field experiments are needed in order to accurately reveal the yield losses in each cultivar due to the infection with each PVY isolate.

Visual symptoms are relied on for the management (e.g., rogueing) and inspection of seed potato crops during the growing season in North America. In this study, the difficulty for symptombased identification of PVY-infected plants is demonstrated. Although a certain degree of symptoms, mainly mild mosaic, was observed in most cultivars with most PVY isolates, the symptoms were sometimes only visible at a narrow window of time in both primary and secondary infections. This is particularly true for culti- vars such as CalWhite, Russet Norkotah, and Red LaSoda, as well as virtually all cultivars infected with $\mathrm{PVY}^{\mathrm{N}}$. Evidently, the visual inspections should be supplemented with more special and sensitive testing methods such as ELISA or RT-PCR, as suggested by others $(7,31)$

\section{Acknowledgments}

This research was funded by Agriculture and Agri-Food Canada under the Peer-Reviewed Project number 1389 (X. Nie), and by New Brunswick Department of Agriculture and Aquaculture (M. Singh, A. Sullivan, and X. Nie). We thank Huazhong Agricultural University for financial support to B. Nie, and T. Molen and A. Dilworth for technical assistance.

\section{Literature Cited}

1. Beczner, L., Horváth, H., Romhányi, I., and Förster, H. 1984. Studies on the etiology of tuber necrotic ringspot disease in potato. Potato Res. 27:339352.

2. Chikh Ali, M., Maokac, T., Natsuakib, T., and Natsuaki, K. T. 2010 $\mathrm{PVY}^{\mathrm{NTN}-\mathrm{NW}}$, a novel recombinant strain of Potato virus $Y$ predominating in potato fields in Syria. Plant Pathol. 59:31-41 


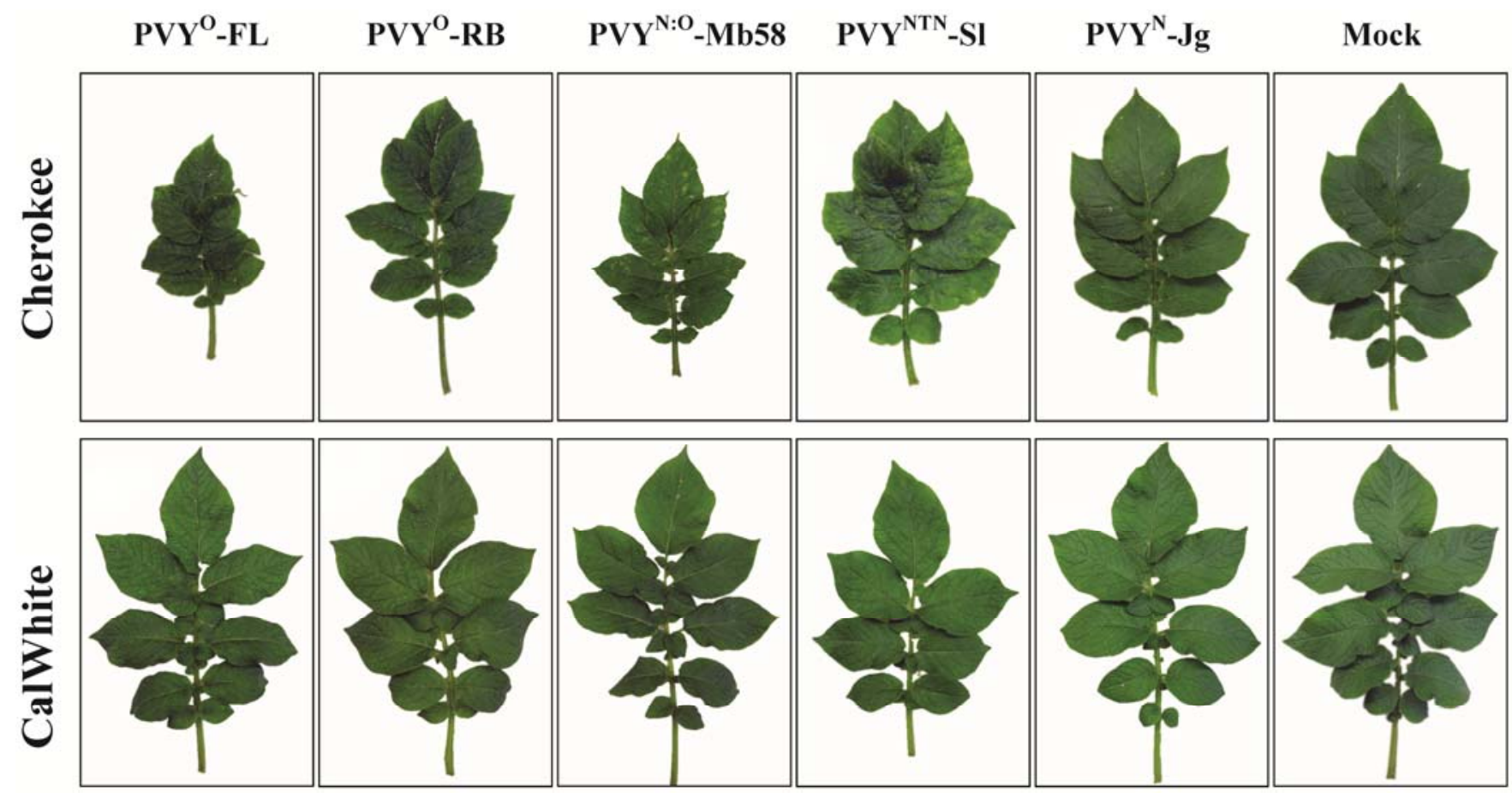

Fig. 5. Leaf symptoms of 'Cherokee' and 'CalWhite' in secondary infections with Potato virus Y (PVY) isolates in the greenhouse at 49 days post plant emergence. Experiments were repeated two times, and similar results were obtained. Pictures shown here were taken from the second repeat.

3. Crosslin, J. M., Hamm, P. B., Hane, D. C., Jaeger, J., Brown, C. R., Shiel, P. J., Berger, P. H., and Thornton, R. E. 2006. The occurrence of PVY $\mathrm{PVY}^{\mathrm{N}}$, and PVY ${ }^{\mathrm{N}: \mathrm{O}}$ strains of Potato virus $Y$ in certified potato seed lot trials in Washington and Oregon. Plant Dis. 90:1102-1105.

4. de Bokx, J. A., and Huttinga, H. 1981. Potato virus Y. Number 242 in: Description of Plant Viruses. Commonw. Inst./Assoc. Appl. Biol. Kew, England.

5. Draper, M. D., Pasche, J. S., and Gudmestad, N. C. 2002. Factors influencing PVY development and disease expression in three potato cultivars. Am. J. Potato Res. 79:155-165.

6. Glais, L., Tribodet, M., and Kerlan, C. 2002. Genomic variability in Potato potyvirus $Y$ (PVY): evidence that $\mathrm{PVY}^{\mathrm{NW}}$ and $\mathrm{PVY}^{\mathrm{NTN}}$ variants are single to multiple recombinants between $\mathrm{PVY}^{\mathrm{O}}$ and $\mathrm{PVY}^{\mathrm{N}}$ isolates. Arch. Virol. 147:363-378.

7. Gray, S., De Boer, S., Lorenzen, J., Karasev, A., Whitworth, J., Nolte, P., Singh, R., Boucher, A., and Xu, H. 2010. Potato virus Y: an evolving concern for potato crop in the United States and Canada. Plant Dis. 94:1384-1397.

8. Hane, D. C., and Hamm, P. B. 1999. Effects of seed borne potato virus Y infection in two potato cultivars expressing mild disease symptoms. Plant Dis. 83:43-45.

9. Hu, X., He, C., Xiao, Y., Xiong, X., and Nie, X. 2009. Molecular characterization and detection of recombinant isolates of Potato virus $Y$ from China. Arch. Virol. 154:1303-1312.

10. Hu, X., Nie, X., He, C., and Xiong, X. 2011. Differential pathogenicity of two different recombinant PVY ${ }^{\mathrm{NTN}}$ isolates in Physalis floridana is determined by the coat protein gene. Virol. J. 8:207.

11. Karasev, A. V., Hu, X., Brown, C. J., Kerlan, C., Nikolaeva, O. V., Crosslin, J. M., and Gray, S. M. 2011. Genetic diversity of the ordinary strain of Potato virus $Y(\mathrm{PVY})$ and origin of recombinant PVY strains. Phytopathology 101:778-785

12. Karasev, A. V., Nikolaeva, O. V., Hu, X., Sielaff, Z., Whitworth, J., Lorenzen, J. H., and Gray, S. M. 2010. Serological properties of ordinary and necrotic isolates of Potato Virus Y: a case study of $\mathrm{PVY}^{\mathrm{N}}$ misidentification. Am. J. Potato Res. 87:1-9.

13. Lorenzen, J. H., Piche, L. M., Gudmestad, N. C., Meacham, T., and Shiel, P. 2006. A multiplex PCR assay to characterize Potato virus $Y$ isolates and identify strain mixtures. Plant Dis. 90:935-940.

14. Nie, B., Singh, M., Sullivan, N., Singh, R. P., Xie, C., and Nie, X. 2011. Recognition and molecular discrimination of severe and mild $\mathrm{PVY}^{\mathrm{O}}$ variants of Potato virus $Y$ in potatoes in New Brunswick, Canada. Plant Dis. 95:113-119.

15. Nie, X., and Singh, R. P. 2002. A new approach for the simultaneous differentiation of biological and geographical strains of Potato virus $Y$ by uniplex and multiplex RT-PCR. J. Virol. Methods 104:40-54

16. Nie, X., and Singh, R. P. 2003. Evolution of North American PVY ${ }^{\mathrm{NTN}}$ strain Tu 660 from local PVY ${ }^{\mathrm{N}}$ by mutation rather than recombination. Virus Genes 26:39-47.

17. Nie, X., and Singh, R. P. 2003. Specific differentiation of recombinant
$\mathrm{PVY}^{\mathrm{N}: \mathrm{O}}$ and PVYNTN isolates by multiplex RT-PCR. J. Virol. Methods 113:69-77.

18. Nie, X., Singh, R. P., and Singh, M. 2004. Molecular and pathological characterization of $\mathrm{N}: \mathrm{O}$ isolates of the Potato virus $Y$ from Manitoba, Canada. Can. J. Plant Pathol. 26:573-583.

19. Nolte, P. 1997. Why a significant increase in virus and methods of control. Pages 24-26 in: Proc. 16th Annu. Natl. Potato Council Seed Semin. Traverse City, MI.

20. Nolte, P., Whitworth, J. L., Thornton, M. K., and McIntosh, C. S. 2004 Effect of seedborne Potato virus $Y$ on performance of Russet Burbank, Russet Norkotah, and Shepody potato. Plant Dis. 88:248-252.

21. Piche, L. M., Singh, R. P., Nie, X., and Gudmestad, N. C. 2004. Diversity among Potato virus $Y$ isolates obtained from potatoes grown in the United States. Phytopathology 94:1368-1375.

22. Rigotti, S., and Gugerli, P. 2007. Rapid identification of potato virus $Y$ strains by one-step triplex RT-PCR. J. Virol. Methods 140:90-94.

23. Rykbost, K. A., Hane, D. C., Hamm, P. B., Voss, R., and Kirby, D. 1999. Effects of seedborne potato virus Y on Russet Norkotah performance. Am. J. Potato Res. 76:91-96.

24. Salazar, L. F. 1996. Virus symptoms in potato. Pages 25-28 in: Potato Viruses and Their Control. International Potato Center, Lima, Peru.

25. Schubert, J., Fomitcheva, V., and Sztangret-Wisniewski, J. 2007. Differentiation of Potato virus $Y$ using improved sets of diagnostic PCR-primers. J. Virol. Methods 140:66-74.

26. Shukla, D. D., Ward, C. W., and Brunt, A. A. 1994. The Potyviridae. CAB International, Wallingford, England.

27. Singh, M., Singh, R. P., and Moore, L. 1999. Evaluation of NASH and RTPCR for the detection of PVY in dormant tubers and its comparison with visual symptoms and ELISA in plants. Am. Potato J. 75:61-66.

28. Singh, R. P. 1992. Incidence of the tobacco veinal necrotic strain of potato virus $\mathrm{Y}\left(\mathrm{PVY}^{\mathrm{N}}\right)$ in Canada in 1990 and 1991 and scientific basis fo eradication of the disease. Can. Plant Dis. Surv. 72:113-119.

29. Singh, R. P., McLaren, D. L., Nie, X., and Singh, M. 2003. Possible escape of a recombinant isolate of Potato virus $Y$ by serological indexing and methods of its detection. Plant Dis. 87:679-685.

30. Singh, R. P., Nie, X., Singh, M., Coffin, R., and Duplessis, P. 2002. Sodium sulphite inhibition of potato and cherry polyphenolics in nucleic acid extraction for virus detection by RT-PCR. J. Virol. Methods 99:123-131

31. Singh, R. P., Valkonen, J. P. T., Gray, S. M., Boonham, N., Jones, R. A. C., Kerlan, C., and Schubert, J. 2008. Discussion paper: the naming of Potato virus $Y$ strains infecting potato. Arch. Virol. 153:1-13.

32. Tordo, V. M. J., Chachulska, A. M., Fakhfakh, H., Le Romancer, M., Robaglia, C., and Astier-Manifacier, S. 1995. Sequence polymorphism in the 5 'NTR and the P1 coding region of the potato virus $Y$ genomic RNA. J. Gen. Virol. 76:939-949.

33. Whitworth, J. L., Nolte, P., McIntosh, C., and Davidson, R. 2006. Effect of Potato virus $Y$ on yield of three potato cultivars grown under different nitrogen levels. Plant Dis. 90:73-76. 